ISSN 1981-416X

Licenciado sob uma Licença Creative Commons

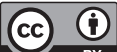

\title{
Participação e representatividade nas pesquisas sobre os Conselhos Municipais de Educação
}

\author{
Participation and representativeness in researches on \\ Municipal Councils of Education
}

\section{Participación y representatividad en las investigaciones sobre los Consejos Municipales de Educación}

\section{Camila Alberto Vicente de Oliveira ${ }^{[a]}$, Egeslaine de $\mathrm{Nez}^{[\mathrm{b}]^{*}}$}

[a] Universidade Federal de Goiás (UFG), Regional Jataí (REJ), Jataí, GO, Brasil

[b] Universidade Federal de Mato Grosso (UFMT), Campus Universitário do Araguaia (CUA), Barra do Garças, MT, Brasil

\section{Resumo}

Na organização dos sistemas e redes municipais de educação, os Conselhos Municipais de Educação (CMEs) podem assumir um espaço importante na proposição de políticas educacionais que apoiem o desenvolvimento de uma escola de qualidade socialmente referenciada. Diante disso, este texto tem por objetivo contribuir com o avanço na produção do 
conhecimento sobre os CMEs, sua natureza, funções e relevância, tomando por base como as pesquisas realizadas no estado de Goiás sobre a temática debatem a participação e a representação social nesses Conselhos. Para tanto, realizou-se o estado do conhecimento em dissertações e teses nos Programas de Pós-Graduação em Goiás. Foram encontrados cinco estudos envolvendo os CMEs, com diferentes objetos, porém a análise dos dados permitiu inferir que não há nenhuma pesquisa que aborde diretamente a questão da participação e da representação social nos Conselhos. Contudo, considerando que essas categorias são elementos fundamentais na implementação da gestão democrática, todos os estudos abordam essa problemática destacando que nos conselhos pesquisados ainda se perpetuam práticas burocráticas e há pouca representatividade. Além disso, ainda estão extremamente atrelados ao poder executivo municipal, minimizando seu potencial e sua atuação no que se refere à mediação dos interesses da comunidade e à organização da educação pública.

Palavras-chave: Conselhos municipais de educação. Participação social. Estado de conhecimento.

\section{Abstract}

In the organization of municipal education systems, the Municipal Councils of Education (CMEs) can take on an important role in proposing educational policies that support the development of a socially referenced quality school. Thus, this article aims to contribute to the advancement of the knowledge production about the CMEs, their nature, functions and relevance, based on how researches carried out in the State of Goiás on this thematic debate the participation and social representation in these Councils. To do so, the state of knowledge in dissertations and theses in Post-Graduation Programs in Goiás was stablished. Five researches involving the CMEs with different objects were found; however the analysis of the data allowed inferring that there is no research that directly addresses the issue of participation and social representation in the Councils. Nevertheless, considering that these categories are fundamental elements in the implementation of democratic management, all those studies approach this problematic, emphasizing that in the researched councils these bureaucratic practices are still perpetuated, there is little representativeness. In addition, they are still extremely attached to the municipal executive power, 
minimizing their potential and action regarding the mediation of community interests and the organization of public education.

Keywords: Municipal Councils of Education. Social participation. State of knowledge.

\section{Resumen}

En la organización de los sistemas y redes municipales de educación, los Consejos Municipales de Educación (CMEs) pueden asumir un espacio importante en la proposición de políticas educativas que apoyen el desarrollo de una escuela de calidad socialmente referenciada. Así, este texto tiene por objetivo contribuir con el avance en la producción del conocimiento sobre los CMEs, su naturaleza, función y relevancia, tomando como base cómo las investigaciones realizadas en el Estado de Goiás sobre esta temática debaten la participación y la representación social en esos Consejos. Para eso, se realizó el estado del conocimiento en disertaciones y tesis en los Programas de Posgrado en Goiás. Se encontraron cinco estudios involucrando a los CMEs, con diferentes objetos, pero el análisis de los datos permitió inferir que no hay ninguna investigación que aborde directamente la cuestión de la participación y la representación social en los Consejos. Sin embargo, considerando que estas categorías son elementos fundamentales en la implementación de la gestión democrática, todos los estudios abordan esta problemática destacando que en los consejos investigados aún se perpetúan prácticas burocráticas, hay poca representatividad. Además, aún están extremadamente sujetados al poder ejecutivo municipal, minimizando su potencial y su actuación en lo que se refiere a la mediación de los intereses de la comunidad y la organización de la educación pública.

Palabras clave: Consejos Municipales de Educación. Participación social. Estado del conocimiento. 


\section{Introdução}

Os Conselhos de Educação têm uma importante trajetória histórica e política na organização dos sistemas de educação, ocupando-se, tradicionalmente, de funções normativas e burocráticas e de assessoramento para os governos. Especificamente após a Constituição de 1988 e suas implicações para os regimes de cooperação e financiamento da educação pública, passam a figurar como um ente necessário às redes e aos sistemas de ensino. Nas palavras de Souza e Vasconcelos (2006, p. 44):

Com o estabelecimento do sistema de ensino dos Municípios, previsto na CF de 1988, e regulamentado na Lei 9.394/96, há uma reestruturação na organização da educação nacional, considerando as incumbências delegadas a estes e a necessidade de financiamento do Governo Federal, para que tais medidas fossem postas em prática. Dessa forma, os sistemas municipais de ensino deveriam constituir-se como organizações independentes e autônomas, cujas regulamentações e normas seriam previstas por seus próprios órgãos normativos, os Conselhos de Educação.

Basicamente, segundo Gohn (2011) criaram-se três tipos de conselhos no cenário brasileiro do século XX: os criados pelo próprio poder público executivo (com função de mediar suas relações com os movimentos e com as organizações populares); os populares (construídos pelos movimentos populares ou setores organizados da sociedade civil em suas relações de negociações com o poder público), e os institucionalizados (com a finalidade de participar da gestão dos negócios públicos criados por leis originárias do Poder Legislativo).

Ainda para Gohn (2011), os CMEs são canais de participação que articulam representantes da população e membros do poder público estatal em práticas que dizem respeito à gestão de bens públicos. Apostase que podem ser agentes de inovação e espaço de negociação dos conflitos. Entretanto, há uma longa história e um acirrado debate em sua trajetória, visto que envolvem questões relacionadas com as seguintes temáticas: participação, formas de governo e representatividade, natureza 
da esfera pública, divisão de poder local, regional, nacional e global. Além disso, outras são mais abrangentes; todavia, emergem e configuram o cenário em que os conselhos se aportam.

Os conselhos funcionam como mediadores e articuladores da relação entre a sociedade e os gestores da educação municipal. O Programa Nacional de Capacitação de Conselheiros Municipais de Educação PróConselho destaca cinco funcionalidades para esse órgão:

- Normatizar: elaborar as regras que adaptam para o município as determinações das leis federais e/ou estaduais;

- Deliberar: autorizar ou não o funcionamento das escolas públicas e da rede privada de ensino, além de deliberar sobre os currículos;

- Assessorar: responder aos questionamentos e dúvidas do poder público e da sociedade. As respostas dos órgãos são consolidadas por meio de pareceres.

- Fiscalizar: acompanhar a execução das políticas públicas e monitorar os resultados educacionais do sistema municipal (BRASIL, 2004).

O presente texto tem como objetivo contribuir com o avanço nas pesquisas sobre os Conselhos Municipais de Educação (CMEs), tomando por base o estado do conhecimento sobre a temática realizado no Estado de Goiás, destacando o conceito de participação e representação sociais nos conselhos apresentados nesses estudos.

Destaca-se ainda que a investigação está vinculada ao projeto do MCTI/CNPq que se intitulava: "O conselho municipal de educação no Brasil e a qualidade socialmente referenciada do ensino", desenvolvido em parceria com a Universidade Federal de Uberlândia (UFU), Universidade Federal da Grande Dourados (UFGD), Universidade Federal de Goiás (UFG/Jataí), Universidade Federal de Mato Grosso (UFMT/ CUA), Universidade do Estado de Mato Grosso (UNEMAT), entre outras instituições participantes.

A pesquisa assentou-se em Morosini (2015, p. 102) quando afirma que "No Brasil, a consolidação da produção científica sobre Educação 
é ainda incipiente, identificando-se um crescente esforço desta área na construção de estados de conhecimento [...]". Justifica-se, portanto, compreender quais os movimentos da pesquisa em educação diante desse objeto e para isso serão apresentados o percurso metodológico do estudo, os resultados e alguns avanços em torno da problemática em tela.

Este estudo apresenta uma parcela significativa dos dados relativos ao estado da arte/estado de conhecimento produzido ao longo do processo de categorização dos conceitos discutidos no bojo desse projeto. Está dividido em duas partes, além dessa introdução e das conclusões. A primeira trata do processo metodológico utilizado para a construção deste artigo e a segunda apresenta as análises realizadas no levantamento bibliográfico e no estado de conhecimento.

\section{Percurso metodológico}

No que diz respeito aos procedimentos metodológicos, cumpre lembrar que toda investigação é uma atividade que permite elaborar um conjunto de conhecimentos, que orienta atos para sua transformação. Sendo assim, partiu-se da ideia de construir uma problematização sobre a participação e representação da sociedade nos conselhos, trazendo reflexões, em especial, sobre como é abordada nas pesquisas desenvolvidas no Estado de Goiás.

Foi realizado um levantamento bibliográfico que gerou um estado de conhecimento, termo cunhado por Morosini (2006) e Franco (2011) que é compreendido como uma produção acadêmica que sintetiza um dado número de estudos, selecionados sob critérios previamente estabelecidos de uma temática. Deste modo, é um tipo de investigação com caráter bibliográfico que tem como objetivo mapear e apresentar a produção acadêmica de uma determinada temática, sendo uma metodologia inventariante e descritiva sobre o assunto que se quer pesquisar.

O estado de conhecimento pode ser caracterizado como uma modalidade de estudo que apresenta a identificação, o registro e uma 
categorização que levem à reflexão, além de uma síntese sobre a produção científica de uma determinada área, em um espaço de tempo, congregando periódicos, teses, dissertações e livros sobre uma temática específica (MOROSINI, 2015).

Aproxima-se teórica e metodologicamente do que Fávero e Oliveira (2012) consideram como estado da arte, diferindo, no entanto, por focalizarem produções delimitadas por critérios que apontam um conjunto categorial. As análises dos dados coletados se deram por meio da abordagem qualitativa. Triviños (1987) explicita que a pesquisa qualitativa apreende as relações fundamentais dos processos histórico-sociais, em seus movimentos essenciais.

Portanto, a elaboração desse estado de conhecimento apresenta um mapeamento que desvela análises relevantes sobre a produção científica no que tange aos CMEs, apontando os registros existentes nos estudos num estado brasileiro na região centro-oeste.

\section{Participação e representatividade nas pesquisas sobre os CMEs em Goiás}

Este estudo teve como objeto um mapeamento sobre a produção científico-acadêmica sobre os CMEs, evidenciando um estado de conhecimento sobre o assunto a partir de um recorte bibliográfico que compreendeu as teses e dissertações produzidas em Goiás até 2017. A partir dos registros existentes, podem-se tecer análises relevantes sobre a produção científica nos programas de pós-graduação nesse Estado.

Considerando que os marcos regulatórios sobre a constituição dos conselhos tenham se dado a partir da promulgação da Constituição Federal de 1988 e a necessidade de sua implementação tenha se efetivado com a LDB n 9.394/96, Nez, Siebiger e Lima (2016) sinalizam que a composição desse espaço de participação social ainda é recente no atual regime democrático. "Por conseguinte, a produção acadêmica sobre os CMEs 
ainda é, no geral, pouco expressiva, demonstrando um campo profícuo para realização de pesquisas" (p. 14).

Quadro 1 - Pesquisas sobre os CMES no estado de Goiás

\begin{tabular}{|c|c|c|}
\hline Título & Autor(a) & Tipo/Instituição/Ano \\
\hline $\begin{array}{l}\text { Sistema municipal de ensino de Aparecida } \\
\text { de Goiânia/GO: processo de criação, } \\
\text { organização, institucionalização e gestão. }\end{array}$ & Cecília Araújo de Oliveira & $\begin{array}{l}\text { Dissertação } \\
\text { FE - UFG - Goiânia } \\
2006 .\end{array}$ \\
\hline $\begin{array}{l}\text { A municipalização e a institucionalização do } \\
\text { sistema municipal de ensino em Goiatuba- } \\
\text { GO (1997-2004): avanços e retrocessos do } \\
\text { processo de democratização da educação } \\
\text { básica pública. }\end{array}$ & Railda Soares Buzaim & $\begin{array}{l}\text { Dissertação } \\
\text { FE - UFG - Goiânia } \\
2009 .\end{array}$ \\
\hline $\begin{array}{l}\text { Conselhos Municipais de Educação em } \\
\text { Goiás: historicidade, movimentos e } \\
\text { possibilidades. }\end{array}$ & Edson Ferreira Alves & $\begin{array}{l}\text { Dissertação } \\
\text { FE - UFG - Goiânia } \\
2011 .\end{array}$ \\
\hline $\begin{array}{l}\text { Institucionalização dos Conselhos } \\
\text { Municipais de Educação nas capitais } \\
\text { brasileiras: a luta por uma nova hegemonia } \\
\text { política. }\end{array}$ & Paulo Eduardo dos Santos & $\begin{array}{l}\text { Tese } \\
\text { FE - UFG - Goiânia } \\
2014 .\end{array}$ \\
\hline $\begin{array}{l}\text { O direito à educação e à qualidade } \\
\text { socialmente referenciada do ensino: a } \\
\text { atuação do CME de Mineiros/GO. }\end{array}$ & Guilherme Sousa Borges & $\begin{array}{l}\text { Dissertação } \\
\text { Regional Jataí - UFG } \\
\text { - Goiânia } \\
2017 .\end{array}$ \\
\hline
\end{tabular}

Fonte: Organização das autoras (2017).

Foram encontrados cinco estudos sobre os CMEs no estado de Goiás (conforme pode ser observado no Quadro 1, número pequeno se for considerado que existem dois programas de pós-graduação consolidados na Universidade Federal de Goiás (UFG/Goiânia) e Pontifícia Universidade Católica (PUC/GO), em atividade respectivamente desde 1986 e 2001. Desses estudos, quatro foram concluídos na UFG/Goiânia, na linha de pesquisa Estado e política educacional e um, na UFG/Regional Jataí, na linha Políticas educacionais, gestão e formação de professores.

Mesmo tendo objetos distintos, as investigações citadas nesse estado de conhecimento apresentado buscam debater sobre a história, formação e atuação dos CMEs, o que perpassa, necessariamente, pela 
forma de organização da participação e da representação sociais, considerando-o como um dos fundamentos para a atuação dos Conselhos.

Ao refletir sobre a organização do sistema municipal de Aparecida de Goiânia, Oliveira (2006) teve como objetivo analisar a conformação desse sistema em um contexto de descentralização da educação após a promulgação da Constituição de 1988 e os embates políticos decorrentes desse processo no município lócus do estudo. Realizou, para isso, um estudo de caso e elegeu como aspectos preponderantes para as análises, dentre outros: princípios da gestão democrática no município, a criação do sistema municipal de educação, a elaboração e o conteúdo do plano municipal de educação e a institucionalização do conselho.

Ao apresentar o processo de criação e organização do CME desse município, Oliveira (2006, p. 88-89) aponta que as atividades começaram em 2001 com a escolha dos membros, destacando que, em princípio, já houve o descumprimento da Lei Orgânica (LO) no que se refere à participação e a representatividade da sociedade,

Em primeiro lugar já se percebe que a Lei Municipal n. 2.169/2001 descumpriu a LO. Pela LO, um quarto dos membros deveria ser indicado pelo Legislativo, porém, na Lei 2.169/2001, o Legislativo só tem poder para escolher um representante. Se a LO é a Lei Maior do município, acreditamos que, para não ser ferida, deveria ser reformulada antes de se aprovar uma lei que a contrariasse. Em segundo lugar, a Lei n. 2.169/2001, não cita de quem partirá a escolha dos representantes dos pais e alunos e do representante do quadro docente do ensino superior, fato que deixa margem para o executivo municipal colocar o membro que bem entender.

Moraes (2017, p. 75), ao discutir o controle social na condução de políticas públicas educacionais a partir da Constituição Federal (CF) de 1988, afirma que,

O Constituinte apontou para uma democracia cuja dimensão inclusiva não se contenta com o aspecto delegatório do voto. [...] previu tanto a 
forma representativa como a direta no exercício do poder pelo povo, viabilizando que leis ordinárias disciplinas sem formas de participação social.

A aplicação desse dispositivo nos municípios, conforme debatido por Oliveira (2006) em sua dissertação, revela que há pouca articulação com vistas a garantir, pelo menos no âmbito legal, a representatividade da comunidade educacional e da sociedade organizada, distanciando-se do preconizado na $\mathrm{CF}$.

Em outro estudo encontrado, Buzaim (2009) dissertou sobre a institucionalização do sistema municipal de educação em Goiatuba/GO no período compreendido entre 1997-2004. Vale ressaltar que os CMEs são obrigatoriamente entes constitutivos dos sistemas na perspectiva da descentralização e democratização das políticas municipais, conforme destacado a seguir:

Constituem indicadores de democratização: a) criação, constituição e funcionamento do Conselho Municipal de Educação; b) elaboração coletiva do Plano Municipal de Educação; c) instituição e composição de conselhos escolares, que são formados por representantes de diferentes segmentos da comunidade escolar e local, com funções consultivas, deliberativas, mobilizadoras e fiscalizadoras [...] (BUZAIM, 2009, p. 14).

Partindo desse princípio, segundo Buzaim (2009), nesse município, o CME deveria ser composto por seis membros titulares e seus respectivos suplentes, considerando a representação dos poderes executivo e legislativo, Secretaria Municipal de Educação, professores e dois representantes da sociedade. A análise documental realizada, no entanto, revelou que, além de haver poucas informações acerca da composição do colegiado, o decreto que autoriza e regulamenta o funcionamento do conselho dá plenos poderes ao executivo municipal acerca das proposituras apresentadas e deliberadas pelo Conselho, esvaziando, portanto, o seu sentido participativo e democrático.

Foi verificada, na prefeitura municipal, na Câmara Municipal e na Secretaria Municipal de Educação, a inexistência de decretos ou 
qualquer outro tipo de legislação nomeando os membros desse colegiado. Encontra-se sob a responsabilidade do atual Conselho Municipal de Educação de Goiatuba um livro do Termo de Abertura no qual as reuniões realizadas pelo CME estão registradas em ata. Assim, esse livro tornou-se a único documento utilizado para analisar o processo de constituição do Conselho Municipal de Educação de Goiatuba. De acordo com o registro nas atas do Conselho Municipal de Educação de Goiatuba, a primeira constituição ocorreu no ano dia 7 de abril de 1997, segundo indicações dos poderes executivo e legislativo, associações de professores, de moradores do setor central e de pais e mestres. O Decreto no 5.454, de 3 de junho de 1997, que homologou o regimento interno do Conselho Municipal de Educação, determinou que, após reunião do conselho, seu presidente deveria apresentar ata ao chefe do executivo municipal, para que ele pudesse vetar ou homologar, no todo ou em parte, as matérias aprovadas pelo conselho (BUZAIM, 2009, p. 79).

A pesquisa desenvolvida por Alves (2011) em quatro municípios do estado de Goiás (Anicuns, Nazário, Santa Bárbara de Goiás e São Luís de Montes Belos) objetivou conhecer a história, os movimentos e possibilidades desses Conselhos. Suas conclusões, dialogando com as pesquisas já relatadas, no que se refere à organização e representatividade nos CMEs, destacam que

Observamos que há certo equilíbrio quantitativo de forças na composição dos quatro colegiados ao considerarmos a formação tripartite entre representantes do governo (Administração, Secretarias, Legislativo), do setor educacional (professores, diretores e servidores administrativos de escolas públicas e privadas) e representantes dos segmentos sociais em geral (pais, alunos, instituições como igrejas, associações de moradores, outros conselhos gestores) (ALVES, 2011, p. 135).

O autor revela que analisar apenas a garantia legal de representação dos segmentos ou o equilíbrio quantitativo dos assentos nos colegiados poderia ter sido provado em sua dissertação. Porém, pondera que o aprofundamento nos documentos, especificamente atas dos conselhos em tela, apontam para "a supremacia do discurso e da valorização da 
opinião dos representantes do Poder Executivo (em especial da SMED) e dos trabalhadores educacionais" (ALVES, 2011, p. 136).

Nesse sentido, Bordignon (2013), ao historicizar a representatividade nos Conselhos, afirma que estes foram concebidos como órgãos de assessoramento aos governos e, assim, os conselheiros eram escolhidos pelo Poder Executivo com base no saber acumulado acerca do objeto do colegiado. Atualmente, a gestão democrática pressupõe outros critérios para a representação nos CMES, garantindo a pluralidade e diversidade de saberes e vivências de forma a expressar os interesses e necessidades da sociedade em sua totalidade e não apenas a perspectiva dos gestores dos sistemas.

Dessa forma, completa Alves (2011, p. 138),

[...] os conselheiros precisam ter condições iguais de debate, de exposição e argumentação, e para tanto se faz necessário que principalmente os representantes da sociedade se inteirem do funcionamento da máquina administrativa e das questões educacionais, bem como aprendam sobre a legislação pertinente, ou seja, que se invista na formação dos sujeitos que se ingressam na jornada conselhista.

Para isto, a formação teórica, técnica e política do conselheiro é fundamental para permitir a verdadeira participação decisória nos Conselhos para que esta não se configure e se restrinja em um verniz democrático quando, na verdade, trata-se, a rigor, da chancela aos interesses das Prefeituras. Sendo assim, Gohn (2011) explicita que "[...] ocupar espaços nos conselhos pode ser uma maneira de estar presente em arenas em que se decidem os destinos de verbas e prioridades na gestão de bens públicos; é uma forma de ser ouvido e de continuar lutando para transformar o Estado pela via da democratização das políticas públicas” (p. 109).

Neste sentido, os CMEs podem ser instrumentos para a constituição de uma gestão democrática e participativa, caracterizada por novos padrões de interação entre governo e sociedade em torno de políticas sociais, bem como podem ser estruturas burocráticas; ou ainda, instrumentos de acomodação dos conflitos e de integração dos agentes do sistema. 
Já em Mineiros/GO, a dissertação de Borges (2017), ao debater o papel desse conselho na garantia do direito à educação, expõe que a Lei Municipal que criou o CME garantia a representação da

[...] Secretaria Municipal de Educação; b) um membro da Comissão de Educação da Câmara Municipal de Mineiros; c) um representante do Sindicato dos Trabalhadores da Educação; d) um representante da Associação de Pais do município; e) um representante de entidade estudantil existente na cidade, devidamente reconhecida (BORGES, 2017, p. 153).

Em 2010 houve uma mudança na legislação de criação do conselho, ampliando-se o número de conselheiros e da forma de representação em Mineiros, passando de seis para nove membros. Todavia, destaca Borges (2017, p. 157),

[...] a despeito da evolução no número de conselheiros e na diversidade da participação política, nota-se uma disparidade na representação do Poder Executivo em detrimento dos demais segmentos representados. Enquanto todos os segmentos possuem um representante, a Secretaria Municipal de Educação possui dois. Este dado se mostra relevante na medida em que o poder de controle do Poder Público é potencializado com uma representatividade desigual em um colegiado com apenas nove membros. Assim, mesmo que a Lei Municipal 1.461/2010, tenha inovado com a previsão de eleição ou indicação dos membros do Conselho pelos próprios segmentos da sociedade, esta inovação acabou sendo prejudicada pelo número de assentos ocupados pelo Executivo, por meio da Secretaria Municipal de Educação. Tal fato torna evidente a tentativa do Poder Público em exercer uma forma de controle sobre a atuação do CME.

Esse controle do poder executivo às ações do $\mathrm{CME}$, citado por Borges (2017), indica que o conselho tende a não atuar como mediador dos anseios da população com vistas à garantia de uma educação de qualidade para todos, mas a "composição e a forma de escolha dos conselheiros revelam 
a concepção e a natureza do conselho. Isto porque determina em nome de quem e para quem opinam e decidem" (BORDIGNON, 2013, p. 70).

Vale considerar que, se representativos, os conselhos poderão alterar progressivamente a natureza do poder local. "A medida que eles se tornem atuantes, fiscalizadores das ações do poder público e denunciadores dos lobbies econômicos que pressionam e dominam os aparelhos estatais, eles estarão construindo as bases de uma gestão democrática" (GOHN, 2011, p. 113).

Dentre os cinco estudos sobre os CMEs, apenas um foi realizado em nível de doutorado. Nessa tese, Santos (2014) aborda a institucionalização dos conselhos em três capitais da região centro-oeste: Goiânia, Campo Grande e Cuiabá. Por ter sido realizado em capitais, diferentemente das outras pesquisas que elegeram cidades do interior do Estado de Goiás como loci, a tese traz novos aspectos para a reflexão acerca da participação e representatividade nos conselhos.

O primeiro aspecto diz respeito ao fato de que dos conselhos criados antes da CF de 1988 eram esperados representantes de "reputação ilibada", destaques do autor, e que não tivessem compromisso formal com segmentos da sociedade. No atual, "espera-se que, com os novos arranjos constitucionais centrados na perspectiva do Estado democrático de direito, os conselheiros municipais de educação, na sua maioria, estejam ligados a uma representação política e social" (SANTOS, 2014, p. 187).

Consultando outros trabalhos com ênfase nos CMEs, Souza e Lord (2012), em pesquisa realizada na cidade de Sinop no norte do Estado de Mato Grosso, também constatam os mesmos limites na composição do colegiado. "Isto porque sua lei de criação diz que ele deve ser composto por representantes da sociedade civil, mas ao mesmo tempo limita essa participação quando diz que o órgão tem que ser composto por pessoas de notável conhecimento em educação" (p. 237). Portanto, a letra da lei parece presumir que um pai de aluno da classe trabalhadora ou uma mãe de família que não teve oportunidade de estudar não teriam condições de representar seu grupo no órgão. 
Dessa forma, a investigação ainda revela que, nas três capitais pesquisadas, a função de conselheiros é uma atividade "de relevante interesse social, tendo prioridade sobre quaisquer outras atividades públicas" (SANTOS, 2014, p. 187). Gohn (2011) expõe que as diferentes modalidades de conselhos foram conquistas dos movimentos populares e da sociedade civil organizada. "Eles são um instrumento de representação da sociedade civil e política. Por lei, devem ser também um espaço de decisão" (p. 114).

Outro aspecto que acrescenta às pesquisas circunscritas ao interior de Goiás é que os conselheiros, em Campo Grande e Goiânia recebem compensação financeira (jeton) e, de acordo com o estudo, os conselheiros sujeitos da investigação afirmam que: "a compensação financeira é um dos principais fatores que estimulam a sua participação. Perde apenas para a oportunidade de participar das discussões sobre políticas públicas educacionais no município e é tão importante quanto a questão da autonomia deliberativa do CME" (SANTOS, 2014, p. 189).

Bordignon (2013) pondera que é imprescindível apoiar os conselheiros em suas funções de duas formas: a primeira é o apoio técnico e material com materiais e equipamentos adequados; a segunda maneira diz respeito à garantia de ajuda de custo aos conselheiros para aquilo que se refere à participação nos Conselhos. Ressalta, contudo, que esse aspecto gera um debate, pois o apoio financeiro garantiria e estimularia a participação dos representantes da comunidade que não o fazem como atribuição de seu cargo público, o que pode ser compreendido como perda de certa autonomia. "O que garante autonomia do exercício da função de conselheiro é a legitimidade da escolha e o correspondente mandato" (p. 85).

O terceiro aspecto em que avança em relação às dissertações é que a tese constatou que, nas grandes capitais estudadas, parte dos conselheiros tem experiência político-partidária e sindical

Quanto à experiência dos conselheiros participantes da pesquisa em atividades políticas, sociais ou de controle social, verificou-se que $77 \%$ assinalaram que estão tanto filiados a partidos políticos quanto vinculados a sindicatos de classes, ou seja, são conselheiros que, em tese, 
possuem minimamente uma formação política, o que pode contribuir para a elevação das discussões e definições de políticas educacionais nos CMEs (SANTOS, 2014, p. 193).

Concordando com Santos (2014) que, por um lado, a filiação partidária e sindical eleva a qualidade do debate, por outro lado, a atividade conselhista pode se limitar a um dos espaços de disputa de conviç̧ões e defesa de grupos.

Deste modo, desvelar como as pesquisas sobre os CMEs realizadas no estado de Goiás abordam a questão da participação e da representatividade social é fundamental uma vez que os estudos, mesmo sem ter esses conceitos como objetos, sugerem que a participação, apesar de constituir-se como essência da gestão democrática, ainda se dá de forma burocrática, cartorial e com pouca ou nenhuma autonomia em relação ao poder executivo municipal.

Segundo Lima (2011) as investigações sobre políticas educacionais, Estado, democracia, descentralização, participação e autonomia se constituem numa análise teórica importante para compreender a categoria controle social. Essa corresponde a uma perspectiva de participação, de ação democrática, de instrumentalização de mobilizações e práticas que influenciem tanto no plano decisório governamental quanto no planejamento e financiamento dos serviços públicos.

Teixeira (2004, p. 705), em pesquisa realizada em CMEs do interior do Estado de Minas Gerais, ao avaliar a representatividade desses conselhos, o faz de forma semelhante às conclusões dos estudos realizados em Goiás, quando mesmo as representações de pais e membros da sociedade civil organizada são preenchidos por docentes e profissionais da educação, restringindo a autonomia dos Conselhos aos interesses dessas categorias. Assim,

Como se pode perceber, a composição dos conselhos abre espaço para uma representação mais democrática. Em primeiro lugar, porque neles a participação dos profissionais de ensino apresenta-se de forma diversificada e reforça a representação por categoria. Em segundo lugar, porque neles se conta com a representação da sociedade civil, permitindo sua participação na definição da política de educação a ser levada a cabo no município. Cabe atentar, no entanto, para o fato de que, se, por um lado, essa forma de representação supera as escolhas personalistas e 
clientelistas que podem comprometer a gestão participativa do trabalho dos conselhos, por outro lado, pode assumir um caráter de representação corporativa na defesa dos interesses da categoria.

Lord (2006) também considera que as características de um órgão de participação democrática, como é o caso do CME em estudo, refletem as especificidades da sociedade num determinado tempo e espaço. De um modo geral, as dificuldades vivenciadas pelo CME de Sinop são semelhantes àquelas vividas pela democracia local. Isso significa dizer que "o histórico da formação desta sociedade, as condições de desigualdade, o precoce processo de democratização e a fragilidade dos espaços de controle social sobre o governo pesam sobre o papel do Conselho em estudo" (p. 239).

Conforme explicita Lima (2009, p. 1-2) os conselhos devem atuar como mediadores dos interesses da sociedade e por essa razão garantir a pluralidade de representação que é o fundamento para a democracia na atuação dos CMEs.

Como processo, a democracia prescinde do conflito - elemento central da democracia - que aglutina a participação e os instrumentos democratizadores da sociedade e das organizações sociais. Explicitando melhor, podemos ter participação sem ter relações democráticas, mas não podemos ter relação democrática sem participação. [...] A participação é, assim, o elemento central da democracia, é como se fosse um termômetro que medisse a "temperatura" da democracia (grifo do autor).

Em sendo desta forma, as pesquisas indicam que há um grande caminho a percorrer, visto que os municípios organizaram e mantêm em funcionamento seus respectivos conselhos dada sua vinculação com os sistemas e o financiamento da educação pública. No entanto, sua consolidação enquanto lócus de mediação e definição de políticas voltadas para a maioria da população exige a garantia da efetiva participação da comunidade, representação plural perpassando desde a configuração legal dos CMEs, a eleição e o mandato dos representantes, formação técnica e política dos conselheiros e autonomia dos Conselhos. Esses aspectos não estão contemplados nos CMEs pesquisados em Goiás e nos outros Estados citados. 


\section{Considerações finais}

A pesquisa realizada apontou que é necessário avançar na produção de estados de conhecimento a fim de verificar avanços e lacunas na pesquisa em educação. No estado de Goiás, há 5 (cinco) programas de pós-graduação (UFG — campi Goiânia, Jataí e Catalão, PUC/GO e Universidade Estadual de Goiás) com linhas de pesquisa voltadas ao estudo das políticas e organização da educação. O PPGE da UFG, em Goiânia, por exemplo, tem mais de vinte anos de atuação e o primeiro curso de doutorado da Região Centro-Oeste. No entanto, o levantamento de todas as teses e dissertações defendidas nesses programas revelou que existem apenas 5 (4 dissertações e 1 tese) pesquisas que tem como objeto de estudos os CMEs, em suas múltiplas configurações, com diferentes problemáticas.

Foram realizados estudos em cidades da região metropolitana de Goiânia, municípios do interior e três capitais da Região Centro-Oeste. Prioritariamente, as pesquisas se voltaram às formas de organização e funcionamentos dos conselhos nos municípios e não foi localizada nenhuma pesquisa específica sobre a representatividade e participação da sociedade nos CMEs.

Porém, a leitura e análise textuais permitiram inferir que, como a participação e representatividade é condição para a gestão democrática e para a atividade conselhista, todas as pesquisas debateram, em alguma medida, essas questões.

A análise demonstrou que a representatividade ainda é limitada, circunscrita, que, muitas vezes, as representações vêm dos governos municipais e que a participação - com autonomia, formação técnica e política - ainda não é uma realidade nos Conselhos no estado de Goiás. Dessa forma, são retiradas possibilidades de avanços na organização dos Conselhos como entes mediadores de políticas educacionais com vistas à configuração de uma educação de qualidade socialmente referenciada.

Enfim, ressalta-se que as novas práticas constituem um tecido social denso e diversificado que tensiona as formas de fazer política e cria novas possibilidades para o futuro, em termos de alternativas democráticas. Os conselhos enquanto interlocutores públicos podem contribuir para a ressignificação da 
política. Em resumo, os conselhos são um espaço frágil no qual se observam, de um lado, relações, oportunidades e consolidação de espaços democráticos e, de outro, impactos no encaminhamento das demandas e dos resultados para os diferentes setores da sociedade civil organizada que participa dos mesmos.

\section{Referências}

ALVES, E. F. Conselhos municipais de educação em Goiás: historicidades, movimentos e possibilidades. 2011. 209 f. Dissertação (Mestrado em Educação) Faculdade de Educação, Universidade Federal de Goiás, Goiânia: 2011.

BORDIGNON, G. Gestão da educação no município: sistema, conselho e plano. 2. ed. São Paulo: Instituto Paulo Freire, 2013.

BORGES, G. S. O direito a educação e a qualidade socialmente referenciada do ensino: a atuação do CME de Mineiros/GO. 2017. 223 f. Dissertação (Mestrado em Educação) — Regional Jataí, Universidade Federal de Goiás, Jataí, 2017.

BRASIL. Constituição da República Federativa do Brasil 1988. São Paulo: Saraiva, 2007.

BRASIL. Lei $n^{\circ}$ 9.394, de 20 de dezembro de 1996. Estabelece as diretrizes e bases da educação nacional. Disponível em: <http://www.planalto.gov.br/ccivil_03/ Leis/L9394.htm>. Acesso em: 22 mar. 2009.

BRASIL. Programa nacional de capacitação de conselheiros municipais de educação pró-conselho: guia de consulta. Brasília: Ministério da Educação, Secretaria de Educação Básica, 2004.

BUZAIM, R. S. A Municipalização e institucionalização do sistema municipal de ensino em Goiatuba/GO (1997-2004): avanços e retrocessos do processo de democratização da educação básica pública. 2009. 177 f. Dissertação (Mestrado em Educação) — Faculdade de Educação, Universidade Federal de Goiás, Goiânia, 2009. 
FRANCO, M. E. D. P. Construção de conhecimento acerca da qualidade na gestão da educação superior. In: MOROSINI, M. C. (org.). Qualidade na educação superior: reflexões e práticas investigativas. Porto Alegre: EDIPUCRS, 2011. v. 3.

GOHN, M. G. Conselhos gestores e participação sociopolítica. 4. ed. São Paulo: Cortez, 2011. OLIVEIRA, C. A. Sistema municipal de ensino de Aparecida de Goiânia/GO: processo de criação, organização, institucionalização e gestão. 2006. 111 f. Dissertação (Mestrado em Educação) — Faculdade de Educação, Universidade Federal de Goiás, Goiânia, 2006.

LIMA, A. B. Conselho de educação e controle social: a necessidade de movimentos sociais. In: REUNIÃO NACIONAL DA ANPED, 32., 2009, Caxambu. Trabalhos... Caxambu: ANPED, 2009. Disponível em: <http://www.anped.org.br/sites/default/files/gt03-5615-int.pdf >. Acesso em: 03 mar. 2018.

LIMA, A. B. (org.) Estado e o controle social no Brasil. Uberlândia: EDUFU, 2011.

LORD, L. J. D. Limites e dificuldades à gestão democrática: um estudo sobre a área de educação a partir do conselho municipal de Porto Alegre. In: PERONI, V. M.; BAZZO, V. L.; PEGORARO, L. (orgs.). Dilemas da educação brasileira em tempos de globalização neoliberal: entre o público e o privado. Porto Alegre: Universidade Federal do Rio Grande do Sul, 2006.

MORAES, B. M. O papel do controle social na implementação de políticas públicas de educação no Brasil contemporâneo. In: MORAES, B. M. et al. Políticas públicas de educação. Rio de Janeiro: Ministério Público do Estado/Universidade Federal Fluminense, 2017. p. 73-88.

MOROSINI, M. C. Estado do conhecimento sobre internacionalização da educação superior: conceitos e práticas. Educar, Curitiba, n. 28, p. 107-124, 2006.

MOROSINI, M. C. Estado do conhecimento e questões do campo científico. Educação, Santa Maria, v. 40, n. 1, p. 101-116, jan./abr. 2015. Disponível em: <https://periodicos.ufsm.br/reveducacao/article/view/15822>. Acesso em: 16 nov. 2017. 
NEZ, E.; SIEBIGER, R. H.; LIMA, A. B. Estado da arte das pesquisas acerca do conselho municipal de educação (CME): o que dizem as teses e dissertações. In: SEMINÁRIO DE POLÍTICA E ADMINISTRAÇÃO DA EDUCAÇÃO ANPAE CENTRO-OESTE: relações federativas e a construção do sistema nacional de educação (SNE): qualidade da educação brasileira, 9., 2016, Campo Grande. Anais... Campo Grande: UCDB, 2016.

SANTOS, P. E. Institucionalização dos conselhos municipais de educação nas capitais brasileiras: a luta por uma nova hegemonia. 2014. 269 f. Tese (Doutorado em Educação) — Universidade Federal de Goiás, Goiânia, 2014.

SOUZA, D. B; VASCONCELOS, M. C. C. Os Conselhos Municipais de Educação no Brasil: um balanço das referências nacionais (1996-2002). Ensaio: aval. pol. públ. Educ., Rio de Janeiro, v. 14, n. 50, p. 39-56, jan./mar. 2006. Disponível em: <http:// www.scielo.br/pdf/ensaio/v14n50/30406.pdf >. Acesso em: 06 mar. 2018.

SOUZA, R. B.; LORD, L. J. D. Conselho municipal de educação de Sinop: limites e possibilidades na elaboração das políticas públicas educacionais. Eventos pedagógicos, v. 3, n. 3, p. 231-240, ago./dez. 2012.

TEIXEIRA, L. H. Conselhos municipais de educação: autonomia e democratização do ensino. Cadernos de pesquisa, v. 34, n. 123, p. 691-708, set./dez. 2004. Disponível em: <http://www.scielo.br/pdf/cp/v34n123/a09v34123.pdf〉. Acesso em: 17 fev. 2017.

TRIVIÑOS, A. N. S. Introdução à pesquisa em ciências sociais: pesquisa qualitativa em educação. São Paulo: Atlas, 1987.

Recebido: 30/04/2018

Received: 04/30/2018

Recibido: 30/04/2018

Aprovado: 25/05/2018 Approved: 05/25/2018 Aprobado: 25/05/2018 